\title{
Tesis Yerleştirme (p-Hub) Probleminin Yapay Arı Kolonisi Kullanılarak Çözülmesi
}

\author{
Mehmet Fatih Tefek ${ }^{1}$, Mehmet Beşkirli ${ }^{2 *}$ \\ ${ }^{1}$ Kırşehir Ahi Evran Üniversitesi, Kaman Meslek Yüksekokulu, Bilgisayar Teknolojileri Bölümü, Kırşehir, Türkiye (ORCID: 0000-0003-3390-4201) \\ ${ }^{2}$ Şırnak Üniversitesi, Müendislik Fakültesi, Bilgisayar Mühendisliği Bölümü, Şırnak, Türkiye (ORCID: 0000-0002-4842-3817)
}

(Bu yayın HORA 2019 kongresinde sözlü olarak sunulmuştur.)

(First received 1 August 2019 and in final form 24 October 2019)

(DOI: 10.31590/ejosat.637825)

ATIF/REFERENCE: Tefek, M. F. \& Beşkirli, M. (2019). Tesis Yerleştirme (p-Hub) Probleminin Yapay Arı Kolonisi Kullanılarak Çözülmesi. European Journal of Science and Technology, (Özel Sayı), 193-200.

$\ddot{O} \mathbf{z}$

Tesis (p-Hub) yerleştirme problemi, mal, hizmet ve bilgi dağıtım sistemi stratejilerini konumlandırmayı amaçlayan polinomsal zamanda doğrulanabilen karar problemlerinin karmaşıklık sınıfı olarak bilinmektedir. Dağıtım sistemlerinde istenen düzeyde bir hizmet kalitesini kabul edilebilir bir maliyetle elde etmek için birbirine tahsis edilmiş hatlarla birbirine bağlanmış düğümlerden oluşan bir ağ tasarlanabilir. Tasarlanan bu ağın uygun çözüm maliyetli olmayabilir. Bundan dolayı toplam ulaşım maliyetini azaltmatabilmek amacıyla, diğer düğümler için birleştirme veya yönlendirme noktası olarak çalışan bazı tesisler (hublar) kullanılabilir. Taşımacılık yönetimi, kentsel yönetim, servis merkezlerinin konumlandırılması, sensör ağlarının tasarımı, bilgisayar mühendisliği, bilgisayar ağlarının tasarımı, iletişim ağlarının tasarımı, güç mühendisliği, onarım merkezlerinin konumunu, elektrik hatlarının bakımı ve izlenmesi ile imalat sistemlerinin tasarımı gibi sorunların çözümünde bu tür ağları oluştururken hub'lar kullanılmaktadır. Hub'lı zorlu bir nokta, hangi düğümlerin ağ özelliklerinin farklılık gösterebileceğine ve hub konum noktaları olarak kullanılacağına karar vermektir. Hub'lı yer tahsisinde kısa zamandaki iyi bir çözüm, uzun hesaplamalar sonucunda elde edilen en iyi çözümden daha etkilidir. Hem kısa zamanda hemde optimum çözüm elde edebilmek amacıyla p-Hub problemlerinin çözümünde son zamanlarda sezgisel temelli algoritmalar işe koşulmaktadır. Bundan dolayı bu çalışmada p-Hub konum problemini çözmek için Yapay Arı Koloni (YAK) algoritması önerilmiştir. Bu çalı̧̧ada, YAK algoritması p-Hub yer tahsisi problem çözümü için düğüm sayısına bağlı olarak üç farklı durumda uygulanmıştır. Birinci durum merkezde sabit olarak bulunan üç adet tesis ve toplam yirmi düğüm, ikinci durum merkezde sabit altı adet tesis ve bunlara bağlı otuz düğüm, üçüncü durum ise merkezde sabit yedi tesis ve bu tesislere bağlı kırk düğümden oluşmaktadır. YAK algoritması ile elde edilen minimum yer tahsisi maliyet fonksiyonu çözümleri tablolar ve grafiklerle verilmiştir. Elde edilen sonuçlar literatürde yer alan Parçacık Sürü Optimizasyonu sonuçları ile karşılaştırılmıştır. Çalışma sonucunda p-Hub yer tahsisi problem çözümünde YAK'ın daha iyi sonuç elde ettiği görülmüştür. Bundan dolayı yönerilen YAK algoritmasının tesis tahsisi (p-Hub) problemi çözümü için uygun bir yöntem olduğunu göstermiştir.

Anahtar Kelimeler: Tesis (p-Hub) Yerleştirme Problemi, Yapay Arı Kolonisi, Optimizasyon.

\section{Solving Facility Placement (p-Hub) Problem Using Artificial Bee Colony}

\begin{abstract}
Facility (p-Hub) allocation problem is known as the complexity class of decision problems that can be verified in polynomial time aiming to locate the strategies of goods, services and information distribution system. In the distribution systems, a network of nodes interconnected by dedicated lines can be designed to achieve a desired level of service quality at an acceptable cost. The designed
\end{abstract}

\footnotetext{
${ }^{*}$ Sorumlu Yazar: Şırnak Üniversitesi, Müendislik Fakültesi, Bilgisayar Mühendisliği Bölümü, Şırnak, Türkiye, ORCID: 0000-0002-4842-3817, mehmetbes@sirnak.edu.tr
} 
solution of this network may not be cost effective. Therefore, in order to reduce the total transportation cost, some hubs can be used which serve as a fusion or routing point for other nodes. Transportation management, urban management, positioning of service centers, the design of sensor networks, computer engineering, the design of computer networks, the design of communication networks, power engineering, the location of repair centers, maintenance and monitoring of electrical lines, such as the design of manufacturing systems to create such networks in the hub 's are used. A challenging point with hubs is to decide which nodes may have different network properties and be used as hub location points. A good solution in a short time is more effective than the best solution obtained by long calculations. In order to obtain both optimal solutions in a short time, heuristic based algorithms have recently been employed in the solution of p-Hub problems. Therefore, in this study, Artificial Bee Colony (ABC) algorithm is proposed to solve p-Hub position problem. In this study, ABC algorithm is applied in three different cases depending on the number of nodes for p-Hub location allocation problem solving. The first case consists of three fixed plants in the center and a total of twenty nodes, the second case consists of six fixed facilities in the center and thirty nodes connected to them, the third case consists of seven fixed facilities in the center and forty nodes connected to these facilities. The minimum space allocation cost function solutions obtained by $\mathrm{ABC}$ algorithm are given in tables and graphs. The results obtained were compared with the results of Particle Swarm Optimization in the literature. As a result of the study, it was seen that $\mathrm{ABC}$ achieved better results in p-Hub space allocation problem solving. Therefore, the proposed $\mathrm{ABC}$ algorithm has shown that it is a suitable method for the solution of the facility allocation (pHub) problem.

Keywords: Facility location (p-Hub) problem, Artificial Bee Colony, Optimization

\section{Giriş}

Tesis (hub) yerleştirme problemi, konum sorunlarının en önemli konularından biridir. Konum analizi veya k-merkezi problemi olarakta bilinen tesis yerleşim problemi, işlem araştırma ve hesaplama geometrisinin bir dalıdır. Tesis yerleşim problemi farklı tesis aralıkları ile ilgili bazı kısıtlamaları ve ilgili talepleri göz önünde bulundurarak operasyon maliyetini düşürmeye çalışmaktadır. Tesis yeri için karar vermek her türlü işletme için stratejik planlama konusunda kritik öneme sahiptir. Mülk edinimi ve kurulması maliyetli olduğundan tesis yeri ve yer değiştirme operasyonları uzun vadeli yatırımlar olarak değerlendirilebilir. Karar vericiler, kârlı yerler seçmek için farklı coğrafi bölgeler, demografik ve eğilim faktörleriyle daha çok ilgilenmektedir. Bu nedenle gelecekteki olaylar belirsiz ve öngörülemez olduğu sürece sağlam tesis yerlerinin seçiminin önemi artmaktadır.

Tesis yerleşim problemi klasik tesis yerleştirme problemlerinin bir uzantısıdır. Düğümler, öngörülen başlangıç ve varış noktaları arasındaki akışlar için birleştirme, bağlantı ve anahtarlama noktaları olarak çalışan tesislerdir (Farahani vd., 2013). Tesis, birçok dağıtım sistemindeki anahtarlama, aktarma ve sıralama noktaları olarak hizmet veren özel tesisler olarak da tanımlanmaktadır. Tesis yerleşim problemi, tesislerin belirlenmesi ve trafiğin başlangıç - varış noktaları arasında yönlendirmek için tesislerin talep düğümlerinin tahsis edilmesiyle ilgilidir (Alumur ve Kara, 2008).

Tesis yerleştirme problemi uzun yıllardır incelenmiş bir problemdir. Bu problem iki şekilde tanımlanabilir (Sarvari vd., 2018). Birincisi, düğümler arasındaki bağlantılara sahip düzenli bir tam bağlantı düğümleri, ikincisi ise bir tesis ve düğümlerden oluşmaktadır ve sırasıyla Şekil 1 ve Şekil 2'de gösterilmiştir.

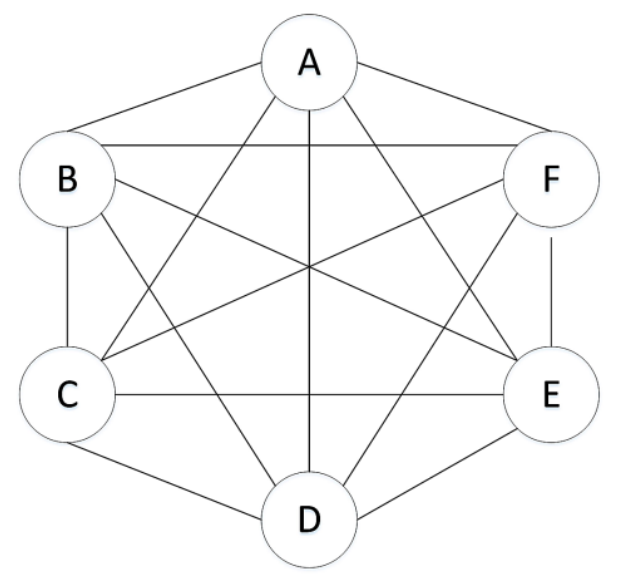

Şekil 1. Düğümler Arasındaki Bağlantılara Sahip Düzenli Bir Tam Bağlantı Dügüumleri

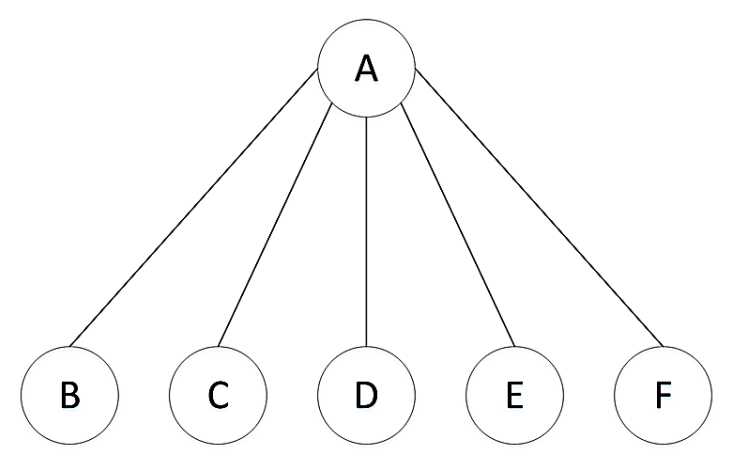

Şekil 2. Bir Tesis ve Bă̆lantı Düğümleri

Tesis yerleştirme problemi literatürde birçok çalışmada yer edinmiştir. Tesis yerleştirme problemi, toplam maliyeti, maksimum mesafeyi ve toplam taşıma süresini en aza indirmeyi amaçlayan matematiksel modeller oluşturulmuş ve sezgisel yöntemler uygulanmıştır (Aversa vd., 2005; Campbell, 2009; Puerto vd., 2016). Pamuk ve Serpil, p-hub problemini çözmek için tabu arama yöntemi kullanarak iki tek tesis yerleştirme işlemi gerçekleştirmişlerdir. Ayrıca ortaya çıkan sonucun iyi olduğunu söylemişlerdir (Pamuk ve Sepil, 2001). Yaman (2008) p-hub yerleştirme problemi için yerel aramaya dayalı bir sezgisel yöntem kullanarak çözmüştür. Mohammadi vd. (2016) iki hedefli tek tesis ile p-hub problemi için doğrusal olmayan bir yöntem geliştirmiştir. Bu sayede ağ üzerindeki belirsizlikleri bulanık mantık yöntemini kullanarak gerçekleştirmiştirler. Marín (2005) çoklu tesis konum problemi için 
bir tam sayılı doğrusal programlama formülasyonu geliştirmiş ve bu model ile literatürde iyi bilinen bir veri ile değerlendirilmiştir. Hsu ve Chen (2007) benzetilmiş tavlama ve tabu arama algoritmalarına dayalı hibrit sezgisel bir yöntem geliştirerek tek tesisli problemlere yönelik sorunlar için bir çözüm bulmaya çalışmışlardır.

Tesis yerleştirme problemi için pek çok uygulama bulunmaktadır. Okullar, itfaiye, hastane gibi kamu binalarının hizmet noktaları ile mağazalar, lojistik hizmet depo merkezleri ve özel şirket tesislerinin konumlandırılması gibi problemler bu kapsamda yer almaktadır. Tesis konumu harita üzerinde istenilen herhangi bir noktaya yerleştirilen modeller sürekli yapıda olup, harita üzerinde belirli noktalara yerleştirme yapılan tesis modelleri ise ayrık yapıda olmaktadır. Bu çalışmada p-hub problemi üzerine durulmuş ve yerleşim konumlarını noktasal olarak düşünüldüğünden noktasal yollar arasındaki bağlantıların şekillendirildiği bir model elde edilmiştir. P-hub problemi $\mathrm{p}$ adet tesisin $\mathrm{n}$ adet talep noktasının ihtiyaçlarını minimum maliyet ile tesislerin yerlerinin belirlenmesi ve hizmet alacak olan talep noktalarının bu tesislere atanmasıdır. Bu problemde $\mathrm{p}=1$ olduğunda 1-hub problemi olmakta ve bütün taleplerin bir tek tesisten karşılandığı durum ortaya çıkmaktadır. $\mathrm{P}=\mathrm{n}$ olduğunda tüm tesislerin kendisine atandığı bir durum ortaya çıkmaktadır. Bundan dolayı bu çalışmada üç durum incelenmiştir. Birinci durumda, üç adet tesis ve toplam yirmi düğüm bulunmaktadır. İkinci durumda, altı adet tesis ve bunlara bağlı otuz düğüm bulunmaktadır. Üçüncü durumda ise yedi adet tesis ve bu tesislere bağlı kırk düğüm bulunmaktadır. Tesis yerleştirme problemi için belirlenen üç durum, yapay arı kolonisi (YAK) algoritması ile çözülmüş ve minimum yer tahsis maliyeti elde edilmiştir.

\section{Materyal ve Metot}

\subsection{Yapay Arı Kolonisi}

Yapay arı kolonisi algoritması (YAK) Karaboğa tarafından 2005 yllında geliştirilmiş sürü tabanlı bir arama algoritmasıdır (Karaboga, 2005). Doğada arıların besin arama davranışları insanlara ilham kaynağı olmuş ve bunun neticesinde ise YAK geliştirilmiştir (Karaboga ve Akay, 2009). YAK'ta arıların bütün davranışları bire bir modellenmemiştir ancak bazı varsayımlarda bulunulmuştur (Karaboga ve Basturk, 2007). Şekil 3 'te gösterildiği üzere kâşif arılar kovan çevresinde rastgele olarak besin kaynağı aramaya başlarlar. Besin kaynağı keşfinde bulunan kâşif arı bulduğu besin kaynağından kovana nektar taşımaya başlar. Kovana gelen arı nektarı boşalttıktan sonra üç olasılık söz konusu olmaktadır (Karaboga ve Basturk, 2008).

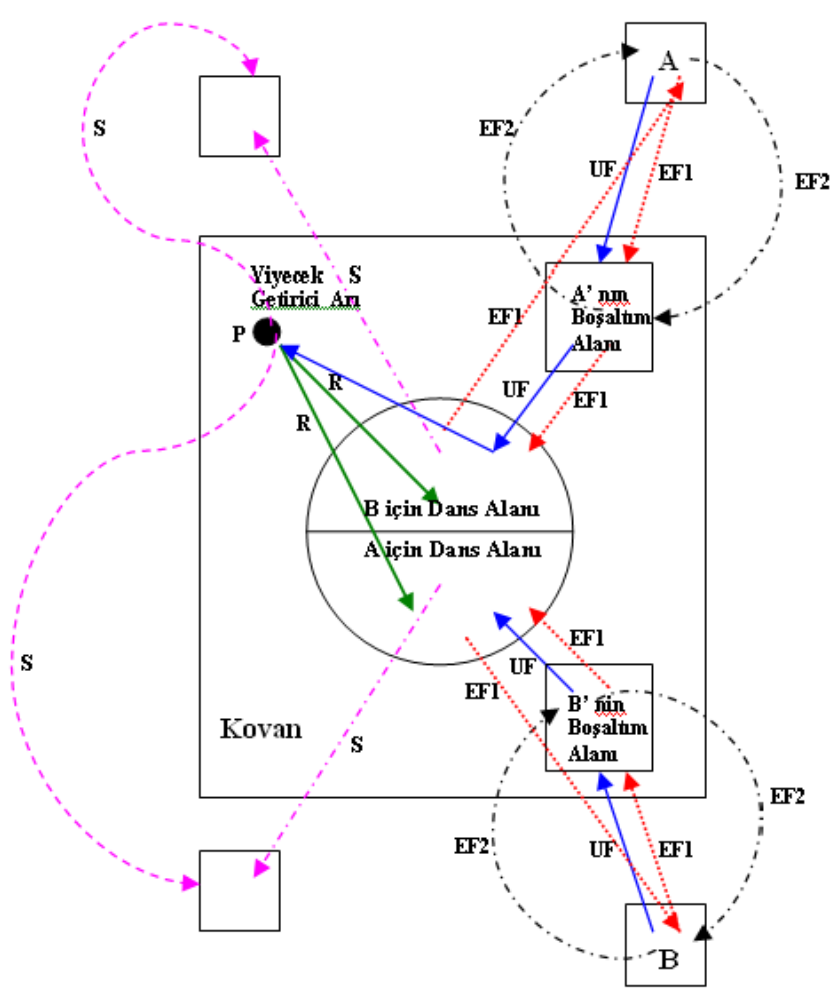

Şekil 3. Arıların Hareket Alanı (Küçüksille ve Tokmak, 2011)

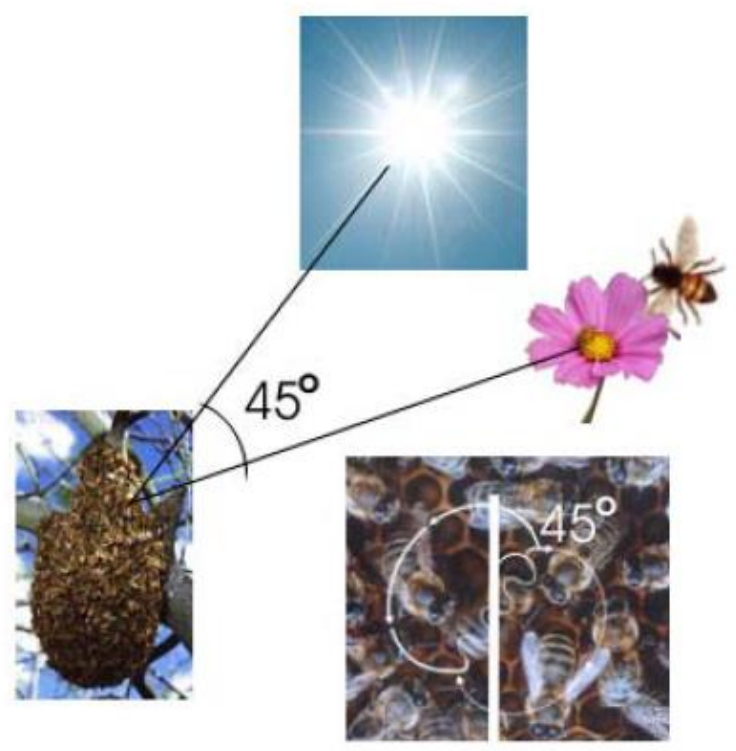

Şekil 4. Arıların Kovan, Işılk ve Yiyecek İlişkisi

Bunlar; 1- Dans alanına giderek besin kaynağı ile ilgili bilgiyi diğer arılarla paylaşmaktır, 2- Hiç bilgi vermeden doğrudan besin kaynağına yönelmek ya da bulduğu besin kaynağını terk ederek yeniden kâş̧if arı olmaya devam etmektir, 3- Kovanda bekleyen gözcü arılar da izledikleri dansa göre ilgili besin kaynağına yönelmektir.

YAK algoritmasının süreçleri ve temel adımları aşağıdaki gibi sıralanmış olup Şekil 5 'te ise YAK algoritmasının akış şeması verilmiştir;

1- Başlangıç yiyecek kaynağı bölgelerinin üretilmesi

2- (Repeat) Tekrar

e-ISSN : 2148-2683 


\section{Avrupa Bilim ve Teknoloji Dergisi}

3- İş̧i arıların yiyecek kaynağı bölgelerine gönderilmesi

4- Olasılıksal seleksiyonda kullanılacak olasılık değerlerinin görevli arılardan gelen bilgiye göre hesaplanması

5- Gözcü arıların olasılık değerlerine göre yiyecek kaynağı bölgesi seçmeleri

6- Kaynağı bırakma kriteri: limit ve kâşif arı üretimi

7-(Until) çevrim sayısı=Maksimum çevrim sayısına eşit olana kadar tekrar et

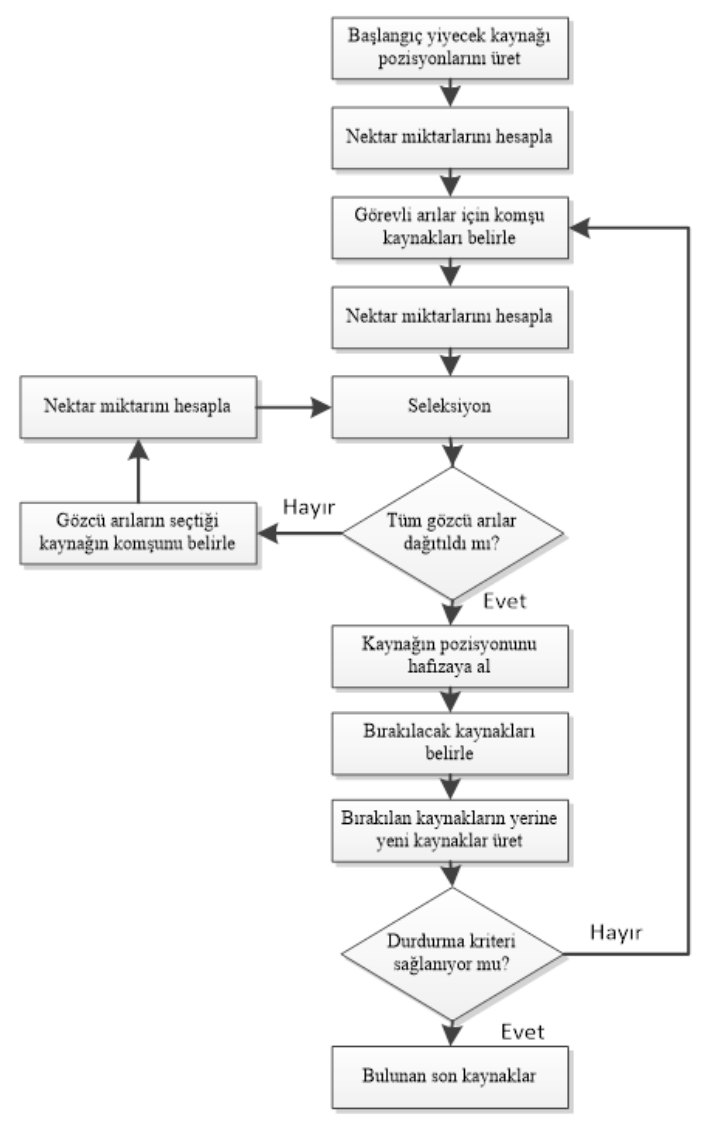

Şekil 5. YAK Algoritmasının Akış Şeması (Alpaslan vd., 2013)

\subsection{Tesis Yerleştirme (p-Hub) Problemi}

Tesis yerleştirme problemi gerçek dünya problemlerinden biri olup sıklıkla optimizasyon teknikleri ile çözülmektedir. Hem özel sektör firmaları tarafindan hem de kamu kurumları tarafından bu problem ile karşı karşıya kalmaktadırlar. Resmi kuruluşlar hizmetin en üst seviyede olacağı yerlerin konumunu belirlerken çok önemli bir karar alma durumunda kalmaktadırlar. Özel sektör firmaları ise üretim merkezi ile depo arasındaki mesafe yerlerini belirlemek için çok önemli bir karar alma durumunda kalmaktadırlar (Ozcakar ve Bastı, 2012). Tesis yerleştirme problemi genellikle $\mathrm{n}$ adet tesisin $\mathrm{m}$ adet konuma (n'nin m'den küçük olası durumunda) taşıma maliyetlerini minimize ederek yerleştirme işlemini gerçekleştirmektedir (Tavakkoli-Moghaddain ve Shayan, 1998). Yani herhangi bir hizmet veren tesisin bazı kısıtları ve aynı zamanda müşteri talepleri de dikkate alınarak maliyetlerin minumum düzeyde olması sağlanmakta ve tesisin uygun konumlara yerleştirme işlemi başarı ile gerçekleşmektedir. Tesis yerleştirme probleminde tesislerin coğrafik olarak farklı konumlarda yerleştirme ya da sadece tesis yeri seçme problemi olarak düşünülmemelidir. Örneğin, bir porselen fabrikasındaki tezgâh ve departmanların yerleştirme işleminde p-Hub problemi rahatlıkla kullanılabilmektedir. P- Hub probleminde yerleştirilen tesislerin hizmet alınacak talep noktalarının en yakın tesise atanması konusunu da ele alınmaktadır. Bu problemin amacı, $\mathrm{p}$ adet tesis yerlerinin en uygun şekilde belirlenmesi için talep ağırlıklı toplam mesafenin en az olmasıdır.

Tesis yerleştirme probleminde düğüm ( $\mathrm{n}$ adet) ve açılacak olan tesisten ( $\mathrm{p}$ adet) oluşan bir modelin olası çözümlerin sayısı Denklem 1'de verilmiştir.

$$
\left(\begin{array}{l}
n \\
p
\end{array}\right)=\frac{n !}{p !(n-p) !}
$$

Tesisler ile talep noktaları arasında oluşan toplam maliyeti minimize eden amaç fonksiyonun formulü Denklem 2'de gösterilmiş̧ir. 


$$
\min \sum_{i=1}^{n} \sum_{j=1}^{n} a_{i} d_{i j} z_{i j}
$$

Denklem 3 ile her talep noktası yalnız bir tesise atanmaktadır. Bu sayede bir talep noktasının tüm talepleri sadece bir tesiste karşılanması sağlanmıştır.

$$
\sum_{j=1}^{n} z_{i j}=1 \quad \forall i \quad i, j=1,2, \ldots, n
$$

Kapalı olan bir tesise talep noktası atamasının yapılmaması için Denklem 4 kullanılmıştır. Böylelikle tutarlılık sağlanmıştır.

$$
z_{i j \leq y_{i}} \forall i \quad i, j=1,2, \ldots, n
$$

Açılacak olan tesis sayısının, p adet ile sınırlandırılması işlemi Denklem 5 ile gerçekleştirilmiş̧ir.

$$
\begin{array}{r}
\sum_{j=1}^{n} y_{i}=p \\
z_{i j}, y_{j} \in\{0,1\} \quad i, j=1,2, \ldots, n
\end{array}
$$

Karar değişkenleri ise aşağıdaki gibidir;

$$
\begin{aligned}
& z_{i j}= \begin{cases}1, & \text { ĕger } i \text { müșterisi } j \text { tesisine atanmışsa } \\
0, & \text { diğer durumda }\end{cases} \\
& y_{j}= \begin{cases}1, & \text { ĕger j noktasında bir tesis açılmışsa } \\
0, & \text { diğ } \text { er durumda }\end{cases}
\end{aligned}
$$

Burada $n$ toplam talep noktası sayısını, $a_{i}$ i noktasındaki talebi ifade etmektedir. $d_{i j}$ i noktası ile $\mathrm{j}$ noktası arasındaki en kısa mesafeyi, $p$ ise hizmet verecek tesis sayısı olarak tanımlanmıştır. Problemin akış diyagramı Şekil 6 'da verilmiştir.

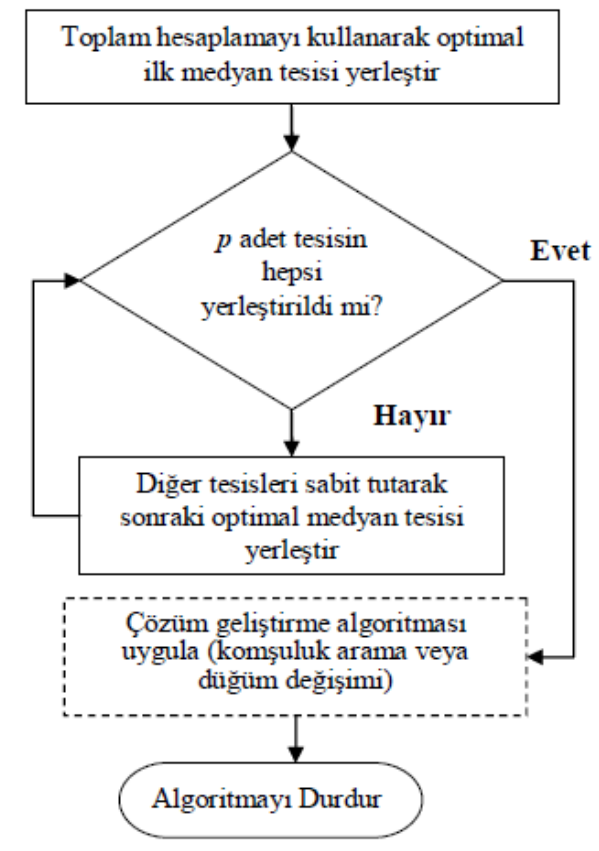

Şekil 6. Problemin Çözümü için Kullanılan Sezgisel Algoritma Akış Diyagramı (Basti, 2012)

\section{Bulgular}


$\mathrm{Bu}$ çalışmada, YAK algoritması p-Hub yer tahsisi problem çözümü için düğüm sayısına bağlı olarak üç farklı durumda uygulanmıştır. Birinci durum üç adet tesis ve toplam yirmi düğüm, ikinci durum altı adet tesis ve bunlara bağlı otuz düğüm, üçüncü durum ise yedi adet tesis ve bu tesislere bağlı kırk düğümden oluşmaktadır. YAK algoritması ile elde edilen minimum yer tahsisi için durumlara göre maliyet fonksiyon çözümlerinin sonuçları tablolar ve grafikler halinde verilmiştir.

Durum 1 için elde edilen sonuç ve yakınsama grafiği Şekil 7 ve 8'de sırasıyla verilmiştir.

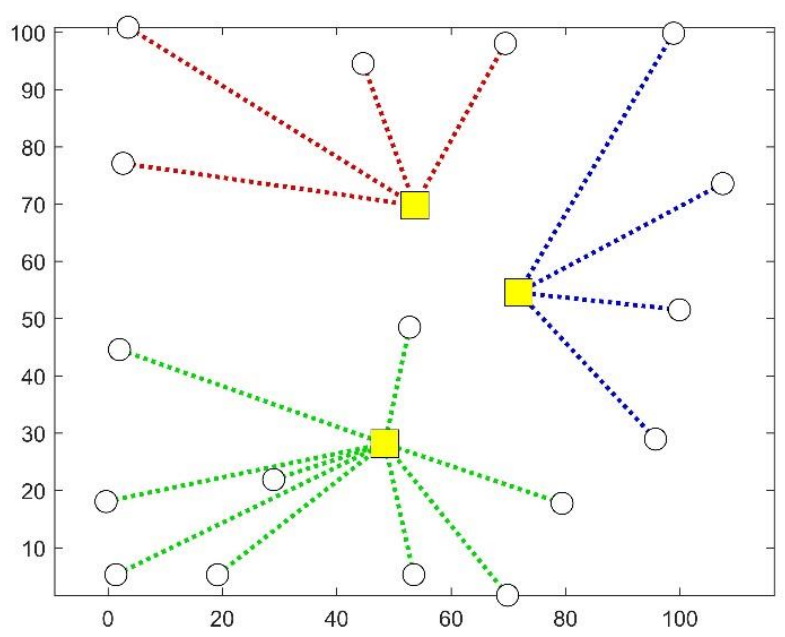

Şekil 7. Durum 1'in Sonuçlart

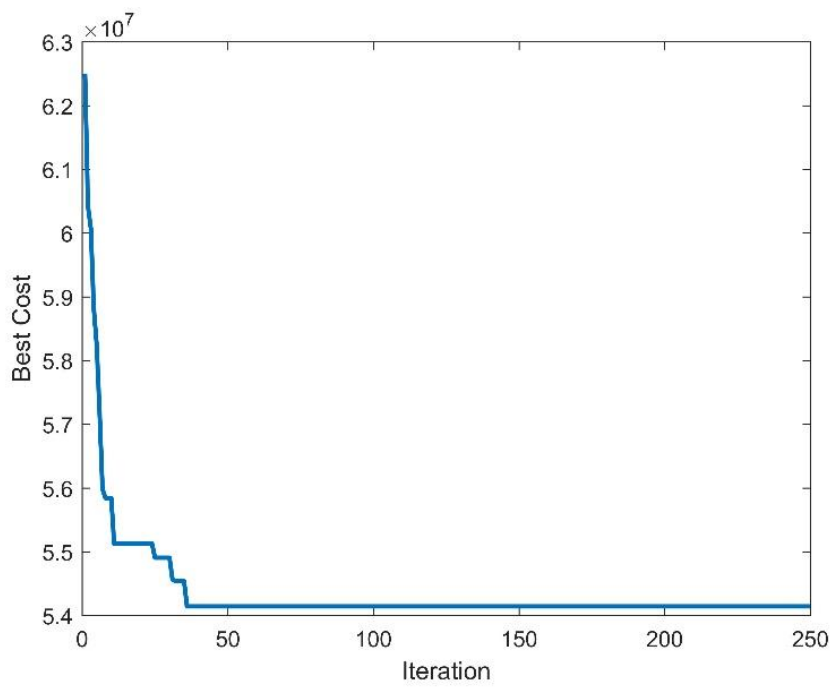

Şekil 8. Durum 1 İçin Yakınsama Grafiği

Durum 2 için elde edilen sonuç ve yakınsama grafiği Şekil 9 ve 10'da sırasıyla verilmiştir.

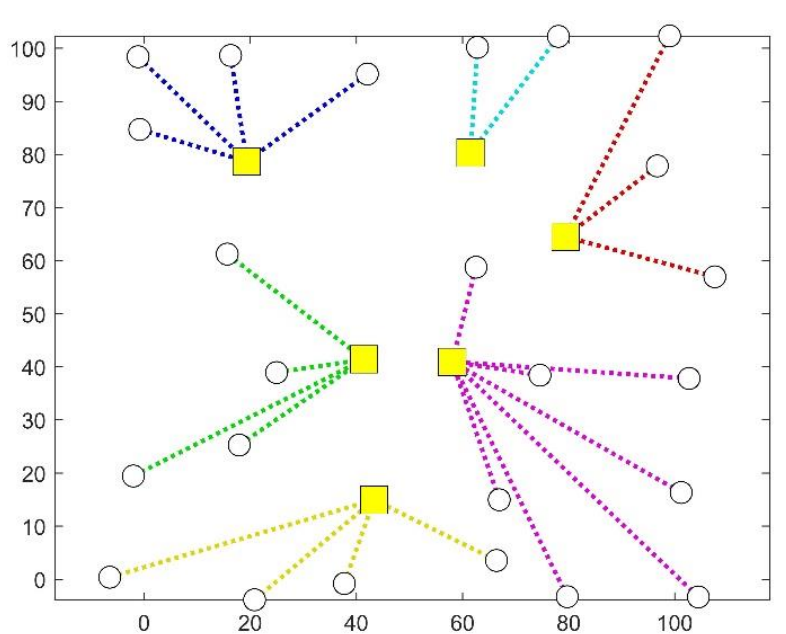

Şekil 9. Durum 2'nin Sonuçları

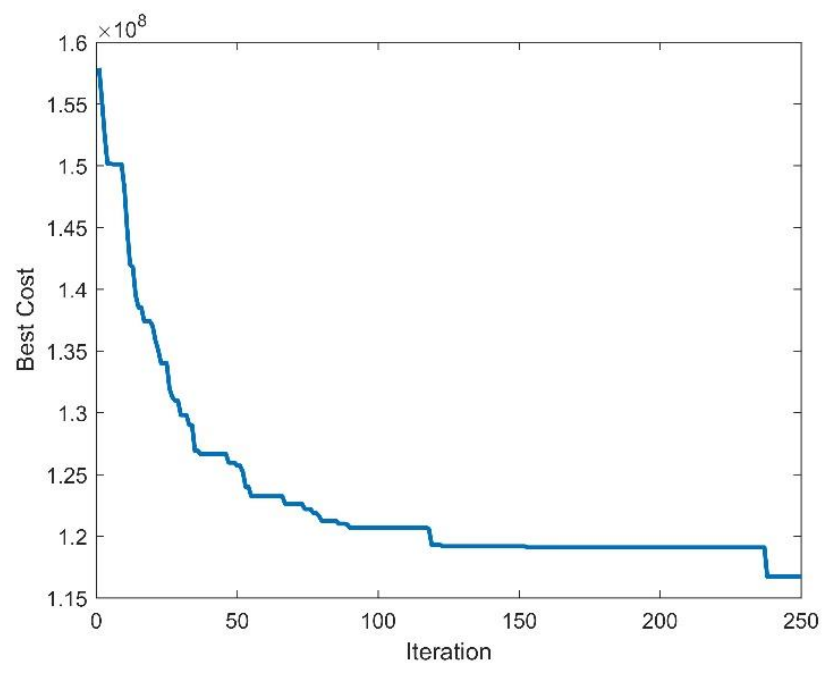

Şekil 10. Durum 2 İçin Yakınsama Grafiği

Durum 3 için elde edilen sonuç ve yakınsama grafiği Şekil 11 ve 12'de sırasıyla verilmiştir. 


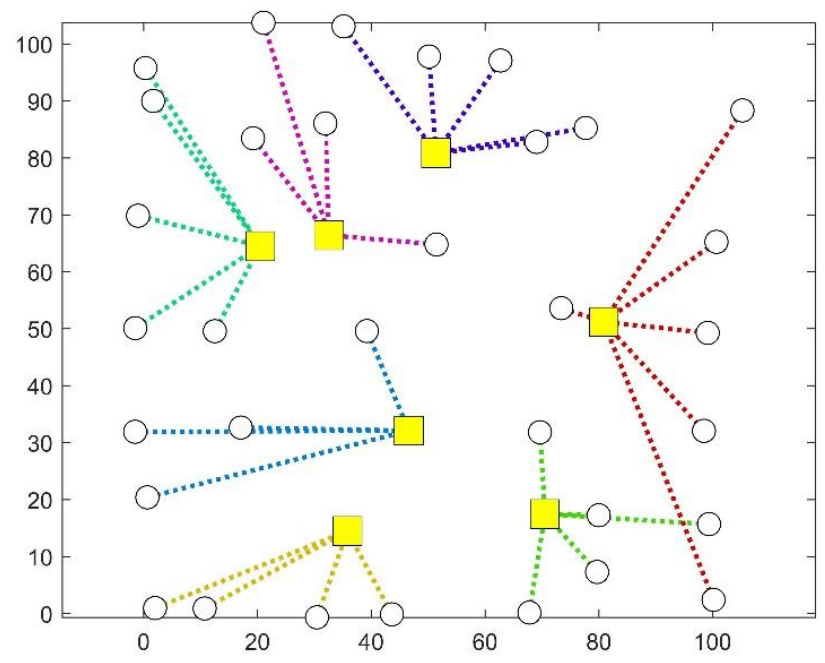

Şekil 11. Durum 3 'nin Sonuçları

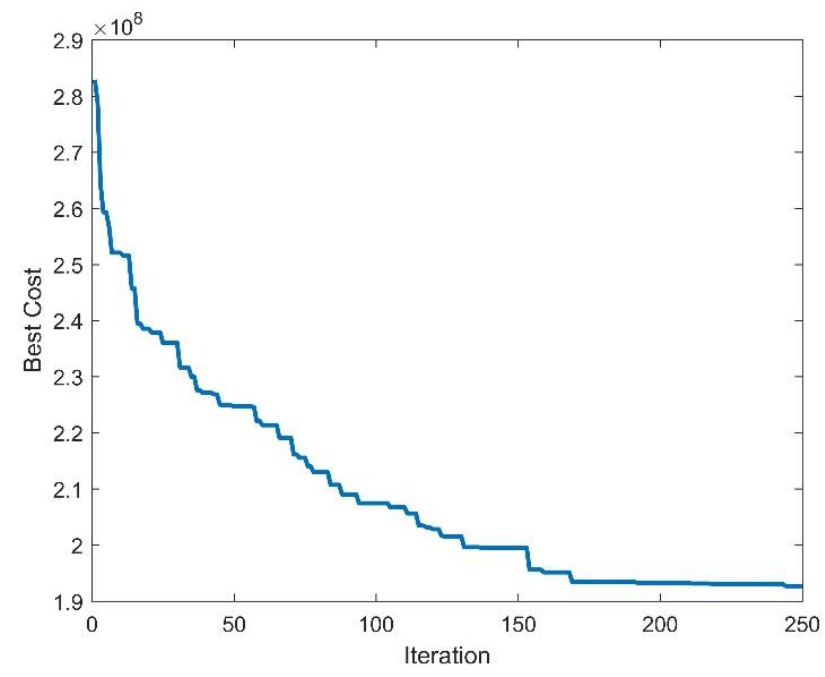

Şekil 12. Durum 3 İçin Yakınsama Grafiği

Üç durum için YAK algoritması aynı şartlarda $10 \mathrm{kez}$ çalıştırılmıştır. Durum1, durum2 ve durum 3 için en iyi maliyet, ortalama maliyet ve standart sapma değerlerinin sonuçları elde edilmiş ve Tablo 1'de verilmiştir.

Tablo 1. YAK ile Elde Edilen Sonuçların Analizi

\begin{tabular}{l|c|c|c}
\hline & En iyi maliyet & Ortalama maliyet & Standart sapma \\
\hline Durum 1 (p-Hub 20) & $5.41 \mathrm{E}+07$ & $5.51 \mathrm{E}+07$ & $2.55 \mathrm{E}+01$ \\
\hline Durum 2 $(p-H u b 30)$ & $1.17 \mathrm{E}+08$ & $1.37 \mathrm{E}+08$ & $3.21 \mathrm{E}+01$ \\
\hline Durum 3 $(p-H u b 40)$ & $1.93 \mathrm{E}+08$ & $2.53 \mathrm{E}+08$ & $1.51 \mathrm{E}+02$ \\
\hline
\end{tabular}

\section{Sonuçlar}

Bu çalışmada, NP-hard problemleri içerisinde yer alan tesis yerleştirme problemi (p-Hub) meta sezgisel yöntemlerden olan YAK algoritması kullanılarak çözümü gerçekleştirilmiştir. P-Hub problemi için üç durum belirlenmiştir. Birinci durumda, üç adet tesis ve toplam yirmi dügüum bulunmaktadır. İkinci durumda, altı adet tesis ve bunlara bağlı otuz düğüm bulunmaktadır. Üçüncü durumda ise yedi adet tesis ve bu tesislere bağlı kırk düğüm bulunmaktadır. Üç durum meta sezgisel bir yöntem olan YAK algoritması ile çözülmüştür. Durum 1 ve Durum 2 için YAK algoritması, tesis yerleştirme probleminin çözümünü uygun olarak gerçekleştirmiştir. Ancak Durum 3'te ise YAK algoritması aynı performansı sergileyememiştir. Bunun sebebi ise problemin düğüm sayısının artmasına bağlı olarak bir tesisin bir düğümünde istenilen sonucu verememesidir. Yani düğüm sayısı ve tesis sayısı arttıkça problemin karmaşıklığı artmakta ve algoritmadan verim alınamamaktadır. Bu çalışma için elde edilen genel sonuç ise p-Hub probleminin çözümü için YAK algoritmasının kullanılabilir bir yöntem olduğu görülmüştür. Düğüm sayısı ve tesis sayısı artması durumunda YAK algoritmasının bu duruma uygun bir şekilde geliştirmesinde fayda olduğu söylenebilir. 


\section{Kaynaklar}

Alpaslan, F., Eğrioğlu, E., Aladağ, Ç. H., İlter, D., \& Dalar, A. Z. (2013). TEK ÇARPIMSAL SINİR HÜCRELİ YAPAY SİNİR AĞI MODELININ EĞITIMI İÇIN ABC VE BP YÖNTEMLERINIIN KARŞILAŞTIRILMASI. Anadolu University of Sciences \& Technology-A: Applied Sciences \& Engineering, 14(3).

Alumur, S., \& Kara, B. Y. (2008). Network hub location problems: The state of the art. European journal of operational research, 190(1), 1-21.

Aversa, R., Botter, R., Haralambides, H., \& Yoshizaki, H. (2005). A mixed integer programming model on the location of a hub port in the east coast of South America. Maritime Economics \& Logistics, 7(1), 1-18.

Basti, M. (2012). The p-median Facility Location Problem and Solution Approaches. AJIT-e, 3(7), 47.

Campbell, J. F. (2009). Hub location for time definite transportation. Computers \& Operations Research, 36(12), $3107-3116$.

Farahani, R. Z., Hekmatfar, M., Arabani, A. B., \& Nikbakhsh, E. (2013). Hub location problems: A review of models, classification, solution techniques, and applications. Computers \& Industrial Engineering, 64(4), 1096-1109.

Hsu, C.-C., \& Chen, Y.-C. (2007). Mining of mixed data with application to catalog marketing. Expert Systems with Applications, $32(1), 12-23$.

Karaboga, D. (2005). An idea based on honey bee swarm for numerical optimization. Retrieved from

Karaboga, D., \& Akay, B. (2009). A comparative study of artificial bee colony algorithm. Applied mathematics and computation, 214(1), 108-132.

Karaboga, D., \& Basturk, B. (2007). A powerful and efficient algorithm for numerical function optimization: artificial bee colony (ABC) algorithm. Journal of global optimization, 39(3), 459-471.

Karaboga, D., \& Basturk, B. (2008). On the performance of artificial bee colony (ABC) algorithm. Applied soft computing, 8(1), 687697.

Küçüksille, E. U., \& Tokmak, M. (2011). Yapay arı kolonisi algoritması kullanarak otomatik ders çizelgeleme. Süleyman Demirel Üniversitesi Fen Bilimleri Enstitü Dergisi, 15(3), 203-210.

Marín, A. (2005). Formulating and solving splittable capacitated multiple allocation hub location problems. Computers \& Operations Research, 32(12), 3093-3109.

Mohammadi, M., Tavakkoli-Moghaddam, R., Siadat, A., \& Rahimi, Y. (2016). A game-based meta-heuristic for a fuzzy bi-objective reliable hub location problem. Engineering Applications of Artificial Intelligence, 50, 1-19.

Ozcakar, N., \& Bastı, M. (2012). P-Medyan kuruluş yeri seçim probleminin çözümünde parçacık sürü optimizasyonu algoritması yaklaşımı. İstanbul Üniversitesi İşletme Fakültesi Dergisi, 41(2), 241-257.

Pamuk, F. S., \& Sepil, C. (2001). A solution to the hub center problem via a single-relocation algorithm with tabu search. Iie Transactions, 33(5), 399-411.

Puerto, J., Ramos, A., Rodríguez-Chía, A. M., \& Sánchez-Gil, M. C. (2016). Ordered median hub location problems with capacity constraints. Transportation Research Part C: Emerging Technologies, 70, 142-156.

Sarvari, P. A., Yeni, F. B., \& Çevikcan, E. (2018). Hub Location Allocation Problems and Solution Algorithms Handbook of Research on Applied Optimization Methodologies in Manufacturing Systems (pp. 77-106): IGI Global.

Tavakkoli-Moghaddain, R., \& Shayan, E. (1998). Facilities layout design by genetic algorithms. Computers \& Industrial Engineering, $35(3-4), 527-530$.

Yaman, H. (2008). Star p-hub median problem with modular arc capacities. Computers \& Operations Research, 35(9), $3009-3019$. 